\title{
Don't you see that its cold! Exploring the roles of cognitive reflection, climate science literacy, illusion of knowledge, and political orientation in climate change skepticism
}

\begin{abstract}
The issue of climate change has become central in recent years as alarming data accumulate. It nevertheless has its critics, consisting of people denying climate change or minimizing the responsibility of human beings in the process. This skepticism partly derives from the complexity of the topic, encouraging people to rely on cognitive shortcuts to grasp the phenomenon. We question the role of cognitive reflection, general and climate changerelated knowledge, overconfidence, and political partisanship (plus additional expected confounding variables) in this process through a package of three studies (total $N=1031$ ). In a first study, we showed that an intuitive mindset predicted greater skepticism relative to an analytical mindset while controlling for cognitive ability and the degree to which individuals value science, suggesting that cognitive sophistication and trust are two key parameters of climate change skepticism. A second study highlighted that climate science knowledge and knowledge overconfidence stood out as strong and independent predictors of skepticism relative to cognitive reflection. A final study revealed that cognitive reflection and climate change knowledge generated less influence on climate change skepticism among conservatives than among liberals and moderates, suggesting that reliance on deliberative thinking and knowledgeability on climate science are not sufficient to mitigate climate change skepticism among conservatives. We discuss the critical interplay between cognitive processes and political partisanship in this ongoing debate.
\end{abstract}

Keywords: Climate change skepticism; Cognitive reflection; Illusion of knowledge; Belief in Science; Numeracy; Science literacy; Political orientation 


\section{Introduction}

The issue of whether climate change has anthropogenic roots spawns heated controversies in the public opinion all over the world. A poll addressing public opinion on climate change in USA (University of Michigan's Center for Local, State, and Urban Policy: 2012) showed that $60 \%$ of people acknowledged a human influence on climate change, leaving a non-negligible segment of climate change skeptics. Skepticism is present despite the large scientific evidence about climate change and the role of mankind in the process: a comprehensive content analysis of climate science publications revealed that $97 \%$ of active climate scholars comply with the conclusions supported by the Intergovernmental Panel Climate Change regarding the anthropogenic influence on climate change (Anderegg, 2010; see also Bedford \& Cook, 2013; Oreskes, 2005). Thus, it is questionable whether this form of pseudoskepticism (Torcello, 2016) does rest or not on informed, well-reasoned critical thinking, or else on climate science denialism. Considering the possibly irreversible environmental damage caused by human activity and the necessity to hearten efficient proenvironmental policies and behaviors, climate change skepticisms represents a major challenge.

The reasons for the opinion gap between climate experts and lay climate change skeptics are multifaceted (Milfont et al., 2015). Among the multiple causations, political ideology is an important factor (Jacques et al., 2008), with conservatives expressing fewer concerns about climate change than democrats (McCright \& Dunlap, 2011; Gromet et al., 2013). Climate change denial has also to do with the endorsement of conspiracy narratives questioning the actual intention of scientific elites (e.g., return on renewable-energy investment, promotion of nuclear power, etc.), leading some people to question the value of scientific speech (Douglas \& Sutton, 2015). 
Of importance is how lay people process information, since cognitive functioning stands as a decisive component of risk perception and skepticism (Van der Linden, 2015). The topic of climate change is filled with explanatory models and concepts which are often difficult to comprehend, generating misconceptions (Markowitz \& Shariff, 2012; Weber \& Stern, 2011). Inaccuracies start from conceptual confusions (e.g., people conflate weather with climate, climate change with ozone depletion; Reynolds et al., 2010) to a weak understanding of dynamic models (e.g., people mistakenly believe that drop in $\mathrm{CO}_{2}$ emissions would cause a drop in $\mathrm{CO}_{2}$ concentrations and global temperature; Sterman \& Sweeney, 2007). Climate change education in classroom remains underinvested and recent evidence suggest that most teachers deliver mixed messages about the anthropogenic nature of climate change, underestimate levels of consensus among experts and report poor knowledgeability about climate functioning (Plutzer et al., 2016). In addition, the use of different framings to characterize the phenomenon (conservatists favoring the label "global warming" when liberals favoring "climate change") impairs the transmission of relevant climate information, making a large-scale educational policy more complicated (Schuldt, Konrath, \& Schwarz, 2011). Thus, the existence of conflicting and misleading sources of information shapes lay people understanding of climate change, leading to decreased perceived risks compared to experts (Whitmarsh, 2011). The possibility that skepticism is informed by individual differences in information processing is warranted, especially in the perspective that climate change understanding requires sound deliberative thinking. Moreover, there is a critical interest to examine the cognitive dimension in conjunction with ideological preferences in order to draw a comprehensive picture of climate change skepticism.

The main purpose of this research is to examine the relative importance of thinking processes, knowledge, self-assessment of knowledge, and political orientation in the development of climate change skepticism. The final purpose is to provide a general picture 
of the way information processing and knowledge levels shape climate change skepticism in the light of political orientation. Study 1 tests the predictive value of cognitive reflection in the context of climate change skepticism above and beyond that of numeracy and science literacy. Study 2 tests the importance of general and climate change-related knowledge and targets the role of overconfidence in knowledge, at both domain-general and domain-specific levels. Finally, Study 3 explores the role of political orientation, for which recent data suggest an important implication in the context of climate change.

\section{Data analyses}

All measures and conditions are reported and all analyses, inclusions/exclusions were determined a priori, with any deviation disclosed. Data were analyzed using R software. Each model was computed while adjusting for potential confounding demographic factors (age, gender, and education). All data, materials, and scripts are available from the Open Science Framework platform (https://osf.io/uzyax/).

\section{Study 1: Climate change skepticism from a dual-processing perspective}

The complexity of the climate change topic inevitably makes lay people rely on cognitive shortcomings. For instance, an averaging bias makes people mistakenly believe that environmentally-harmful actions (e.g., taking one's car to work) can be counterbalanced by environmental-friendly ones (e.g., sorting waste) (Holmgren et al., 2018). There is also evidence of attribute substitution, whereby people use less relevant but accessible information (e.g., current temperature) in place of more relevant but less accessible information (e.g., global climate change patterns) to draw inferences about climate change (Zaval, et al., 2014). Else, high levels of psychological distance to damaging climate change consequences lead to abstract representation of the issue, which mitigates motivation for environmentally-friendly 
initiatives (Ejelöv et al., 2018). If part of the population relies on easy-going informationsearch strategy, the relevance of pointing reasoning as a determinant of skepticism is worth investigating.

That lay people rely on inaccurate mental models or heuristics to apprehend climate change can be investigated under the framework of dual-process theories of thinking. The generic version of the dual-process theory (Epstein, 1994; Evans \& Stanovich, 2013; Kahneman, 2011) postulates that people have two different thinking systems. System 1 (or intuitive system) is fast, does not require much cognitive resources, and is based on an intuitive mode of understanding the world. As such, intuition can be viewed as an easy route by which to understand how the world works even though diagnostic information is lacking and/or of challenging complexity. By contrast, System 2 (or analytic system) is assumed to be slow, deliberative, greedy in limited cognitive resources, and is based on a rational mode of thinking favoring evidence-based information. People's motivation and ability to rely on the analytic system in the presence of a conflicting intuitive response is conceptualized as cognitive reflection (or reasoning cognitive style), which is largely dependent on the ability to detect and override cognitive conflict between the two responses (for a review on conflict detection in reasoning, see De Neys, 2014). People who stay on a System 1 response are labelled intuitive thinkers (or reasoners), and people who move on to a System 2 response are labelled analytical thinkers.

Moreover, climate change skepticism may arise when short-term personal experience is misdiagnosed as incompatible with long-term global warming trends. Short-term ambient temperature can be used as a proxy to such a point that unusually cold weather could help extenuate the plausibility that climate change operates globally (Egan and Mullin 2012). The recent accumulation of data has evidenced that cognitive reflection, compared to cognitive ability, was a better predictor of sensitivity to cognitive biases and endorsement of intuitive 
beliefs. Of critical value in this comprehension is the degree of trust placed in the scientific community and the extent to which people approve of scientific claims. Climate change skepticism might appear when intuitively appealing material about climate outweighs consensual scientific claims due to a lesser belief in the value of science. This rationale mirrors the observation that lay people are unwilling to trust scientific evidence that are counterintuitive in character (Miton \& Mercier, 2015).

Study 1 aims to evaluate the predictive influence of cognitive reflection on climate change skepticism while controlling for general science literacy and cognitive ability, which were used confounded in Kahan et al. (2012). In addition, we will also examine belief in science to control for the possibility that climate change skepticism partly stems from a disregard for the values of science and the scientific community (see Hamilton et al., 2015). Should the motivation and ability to correctly handle cognitive conflict be central components predicting epistemically suspect beliefs, we predict that people more intuitive will hold stronger levels of climate change skepticism above and beyond these variables.

\section{Method}

Sample size determination. An a priori power analysis was conducted using Gpower (Erdfelder et al., 1996). The analysis indicated that a sample size of 360 would be sufficient to detect a significant effect of our predictors with a power of 0.95 and an alpha of 0.05 , based on an effect size $\left(\mathrm{F}^{2}\right)$ of 0.05 . Anticipating drop out and exclusion issues, we requested about 480 participants.

Participants and design: A total of 479 American participants were recruited on the Amazon Mechanical Turk online data collection platform. Among the initial sample, 106 participants did not complete the questionnaire and/or failed to correctly answer the attention check. They were then removed from any further analysis, leaving a final sample of 373 participants (226 
females, 1 "other"; Mean $\left._{\text {age }}=37.6, \mathrm{SD}_{\mathrm{age}}=13.2\right)$ (see supplementary material $\mathrm{S} 1$ for detailed demographic information).

\section{Material:}

\section{Cognitive Sophistication}

Cognitive Reflection Test. To assess reasoning cognitive style, we used a 7-item version of the Cognitive Reflection Test (CRT; 3-item original version by Frederick, 2005; additional items by Thomson \& Oppenheimer, 2016). CRT captures people's ability to override an appealing but incorrect intuitive response. An example of item reads as follow:

In a lake, there is a patch of lily pads. Every day, the patch doubles in size. If it takes 48 days for the patch to cover the entire lake, how long would it take for the patch to cover half of the lake?

When addressing this problem, one would be easily tempted to answer 24 days (as 24 is half of 48). However, this intuitive response is incorrect, and one has to inhibit it to give the correct response (47 days). Participants scored 1 point per correct response, and a composite score was computed (out of 7). Higher scores indicate greater cognitive reflection.

Thinking disposition. To assess thinking dispositions, we used the Actively Open-minded Thinking scale (AOT; Baron et al., 2015; Stanovich \& West, 1997). This 8-item scale assesses people's willingness to reconsider one's beliefs (e.g., 'People should revise their beliefs in response to new information or evidence'). Participants answered using a 5-point scale ranging from 1 (Strongly Disagree) to 5 (Strongly Agree). A composite score was then computed (out of 8), with higher scores reflecting greater open-minded thinking. The scale showed good reliability (Cronbach's $\alpha=.76)$.

Exploring the extent to which cognitive sophistication predicts climate change skepticism, and to avoid collinearity issues (see Berry, \& Feldman, 1985), we transformed 
CRT and AOT into ratio scores, and we combined the two measures into a composite cognitive sophistication score (Cronbach's $\alpha=.78$ ).

Cognitive Ability. We used the 3-item version of the numeracy scale (Schwartz et al., 1997), a task which has been regularly used to assess cognitive ability (e.g., Liberali et al., 2012; Pennycook et al., 2014b). Each item consists in a short mathematical problem that participants have to solve, capturing people's ability in performing simple mathematical operations. An example of problem reads as follow:

Imagine that we rolled a fair, six-sided die 1,000 times. Out of 1,000 rolls, how many times do you think the die would come up even $(2,4$, or 6$)$ ?

A composite score of cognitive ability was then computed out of three, with higher scores indicating greater cognitive ability.

Belief in Science. We used the 10-item belief in science scale (Farias et al., 2013). The scale assesses the extent to which people believe in and value science (e.g., "Science is the most efficient means of attaining truth"). Participants answered using a scale ranging from 1 (Strongly disagree) to 6 (Strongly Agree). A composite score was then computed, with higher scores indicating stronger belief in science. The scale showed excellent reliability (Cronbach's $\alpha=.94)$.

Science Literacy. To assess science literacy, we used the 8 questions used by Kahan et al. (2012), which were originally drawn from the National Science Foundation's "Science and Engineering Indicators", and are largely used as an index of public understanding of basic science (see Allum et al., 2008). An example of question reads as follow: "Electrons are smaller than atoms" [true/false]. Participants scored 1 point per correct answer and a composite score was computed (out of 8).

Climate Change Skepticism. To examine skepticism about climate change, we used 
the 12 items targeting skepticism in the measure originally proposed by Whitmarsh $(2011)^{1}$. The items capture various issues about climate change, such as the causes for climate change (e.g., 'Claims that human activities are changing the climate are exaggerated') or else evidence of climate change itself (e.g., "The evidence for climate change is unreliable"). Participants answered each item using a scale ranging from 1 (Strongly disagree) to 5 (Strongly Agree). The scale showed excellent reliability (Cronbach's $\alpha=.96$ ).

Attention Check. In order to ensure that participants gave sufficient attention to the survey, and to collect good quality data, we included in each study an attention check within the climate change skepticism scale. This item read as follow: "This is a control question, please respond Somewhat Agree". Participants who gave another response were excluded from the analyses.

\section{Results and Discussion}

Table 1 displays semi-partial correlations as well as multiple linear regression model including our variables of interest. Cognitive sophistication $(\beta=-0.24)$ and belief in science $(\beta=-0.18)$ independently predicted climate change skepticism, with cognitive sophistication found to be the strongest predictor (full details in Table 1). Science literacy and numeracy were overshadowed by the inclusion of the other variables.

These results give substance to the notion that cognitive sophistication is a decisive component of public opinion on climate change. People more intuitive seem more likely to endorse skepticism despite scientific evidence and consensus as compared to people more analytic. These data align with research showing that unscientific, epistemically suspect beliefs partly derive from reasoning cognitive style (see Pennycook et al., 2012).

\footnotetext{
${ }^{1}$ The original measure taps four dimensions, but only the first one, which targets the belief component of skepticism, was administered to the participants.
} 
Interestingly, belief in science emerged as an independent predictor of climate skepticism, suggesting that lack of recognition of science as a valuable, reliable method of inquiry belonging to a trustworthy institution also paves the way for climate change skepticism. Hence, for some people, rejection of scientific consensus and climate change scientific claims might stem from an alternative epistemology, leading them to validate or disapprove statements on grounds other than that of science. This tendency reflects environmental antiscience (see Ehrilich, 1996) and is consistent with prior results related to scientific mistrust toward climate models and data (see Malka et al., 2009).

Table 1. Semi-partial correlations and multiple regression results using climate change skepticism as the criterion (Study 1).

\begin{tabular}{|c|c|c|c|c|c|c|c|c|}
\hline Predictor & $b$ & $\begin{array}{c}b \\
95 \% \mathrm{CI} \\
{[\mathrm{LL}, \mathrm{UL}]}\end{array}$ & $\beta$ & $\begin{array}{c}\beta \\
95 \% \mathrm{CI} \\
{[\mathrm{LL}, \mathrm{UL}]}\end{array}$ & $s r^{2}$ & $\begin{array}{c}s r^{2} \\
95 \% \mathrm{CI} \\
{[\mathrm{LL}, \mathrm{UL}]}\end{array}$ & $r$ & Fit \\
\hline (Intercept) & $57.57^{* * *}$ & {$[47.36,67.78]$} & & & & & & \\
\hline Age & 0.01 & {$[-0.09,0.11]$} & 0.01 & {$[-0.08,0.11]$} & $<.001$ & {$[-.00, .00]$} & .03 & \\
\hline Gender & $-5.68 * *$ & {$[-8.33,-3.04]$} & -0.20 & {$[-0.30,-0.11]$} & .04 & {$[.00, .08]$} & $-.18 * *$ & \\
\hline Education & 0.54 & {$[-0.20,1.29]$} & 0.07 & {$[-0.03,0.16]$} & .00 & {$[-.01, .02]$} & .03 & \\
\hline Belief in Science & $-0.20 * *$ & {$[-0.31,-0.09]$} & -0.18 & {$[-0.27,-0.08]$} & .03 & {$[-.00, .06]$} & $-.21 * *$ & \\
\hline Science literacy & -0.49 & {$[-1.50,0.52]$} & -0.05 & {$[-0.16,0.05]$} & .00 & {$[-.01, .01]$} & $-.18 * *$ & \\
\hline Numeracy & -1.52 & {$[-3.16,0.12]$} & -0.10 & {$[-0.21,0.01]$} & .01 & {$[-.01, .02]$} & $-.23 * *$ & \\
\hline \multirow[t]{2}{*}{$\begin{array}{l}\text { Cognitive } \\
\text { sophistication }\end{array}$} & $-18.58 * *$ & {$[-26.95,-10.21]$} & -0.24 & {$[-0.35,-0.13]$} & .04 & {$[.01, .08]$} & $-.33 * *$ & \\
\hline & & & & & & & & $\begin{array}{c}R^{2}=.186^{* *} \\
95 \% \text { CI }[.11, .24]\end{array}$ \\
\hline
\end{tabular}

Note. A significant $b$-weight indicates the beta-weight and semi-partial correlation are also significant. $b$ represents unstandardized regression weights. $\beta$ indicates the standardized regression weights. $s r^{2}$ represents the semi-partial correlation squared. $r$ represents the zeroorder correlation. $L L$ and $U L$ indicate the lower and upper limits of a confidence interval, respectively. $*$ indicates $p<.05, * *$ indicates $p<.01$.

\section{Study 2: Knowledge and illusion of knowledge}


Cognitive sophistication left aside, knowledge-deficit account is often raised for diagnosing lack of adherence to climate change (see Milfont, 2012). The general rationale is that low reception of appropriate scientific information decreases potentiality of climate concerns, thereby reinforcing global immobilism. There is evidence that lack of scientific information is conducive to negative attitude toward science (Rutjens et al., 2018). More specifically, lacking scientific knowledge about specific scientific issues (e.g., innocuousness of GMO foods) increases level of suspicious, mistrustful attitudes toward these issues (McPhetres et al., 2019). Yet, increasing education in these domains helps reverse aversive attitudes (McPhetres et al., 2019). Nevertheless, not only may climate change skepticism be a matter of knowledge, but it may also be a matter of one's own subjective evaluation of climate change knowledgeability. Aside of considering the extent of knowledge people have about a topic, it would be fruitful to evaluate whether self-assessment of domain-specific knowledge is also at stake when it comes to subscribing to climate change skepticism. This is important since overconfidence in one's own knowledge has direct consequences on the motivation to confirm one's prior beliefs (i.e., exhibiting confirmation bias), rather than to seek reliable information (Hart et al., 2009). By contrast, awareness of domain-specific incompetence, or intellectual humility, is more likely to make people rely on evidence, thereby enhancing recognition of scientific authority. That is, illusion of knowledge, captured by inflated self-assessment of one's knowledge (Kruger \& Dunning, 1999), would translate in the pretention to challenge scientific claims without much rigor or sufficient background (see Torcello, 2016). Study 2 tests knowledge levels and illusion of knowledge (or confidence bias) as possible mechanisms explaining climate change skepticism. We investigate knowledge and overconfidence both at the dispositional level (general knowledge) and the specific level (knowledge about climate change topic). We hypothesize that general and climate change knowledge would stand as independent negative predictors of climate change 
skepticism while overconfidence in this knowledge would be a positive condition for holding climate change skepticism. We also maintain our initial hypothesis regarding the role of cognitive sophistication. The relative importance of knowledge and illusion of knowledge will be appraised relative to cognitive sophistication and numerical reasoning by including them in the same linear regression equation.

\section{Method}

Sampling rationale: An a priori power analysis was conducted using Gpower (Erdfelder et al., 1996). The analysis indicated that a sample size of 460 would be required significant effect of our predictors with a power of 0.95 and an alpha of 0.05 , based on an effect size $\left(\mathrm{F}^{2}\right)$ of 0.05 .

Participants and design: A total of 496 American participants were recruited on the Amazon Mechanical Turk online data collection platform. Among the initial sample, 110 participants did not complete the questionnaire and or failed to respond to the attention check question. They were then removed from any further analysis, leaving a final sample of 386 participants (246 females, 1 “other"; Mean $\left._{\text {age }}=40.2, \mathrm{SD}_{\mathrm{age}}=13.2\right)$ (see supplementary material $\mathrm{S} 2$ for detailed demographic information).

\section{Material:}

The climate change skepticism scale (Cronbach's $\alpha=.96$ ), the cognitive reflection measure (CRT) and the cognitive ability measure (Numeracy) were the same as the measures used in Study 1 . We detail the new measures.

Rational Experiential Inventory: We used the 10-item version of the Rational-Experiential Inventory (REI-10 Epstein et al., 1996), which includes two independent constructs operating in parallel. Five items assess people's Need For Cognition (NFC), that is, the extent to which people are inclined towards cognitive effort (e.g., 'I prefer to do something that challenges my thinking abilities rather than something that requires little thought'; Cacioppo \& Petty, 1982). 
Five items assess people's Faith in Intuition (FI), that is, the extent to which people rely on intuition and experience to make decisions (e.g., 'I believe in trusting my hunches'; Epstein et al., 1992). Participants answered NFC (Cronbach's $\alpha=.77)$ and FI (Cronbach's $\alpha=.90)$ using a 5-point scale ranging from 1 (Completely False) to 5 (Completely True). A composite score for each of the dimensions was then calculated. A high score on the NFC scale indicates stronger engagement and enjoyment of cognitive activities and analytical thinking. A high score on the FI scale indicates stronger engagement and enjoyment of intuitive thinking.

Following the same rationale as in Study 1, to avoid collinearity, we transformed CRT, NFC, and FI (reversed) into a ratio score, and we combined the three measures into a cognitive sophistication score (Cronbach's $\alpha=.75)$.

Climate Change Knowledge and Confidence: To assess people's climate change literacy, we relied on the questionnaire proposed by Tobler et al. (2012). The original version captures five dimensions. With regard to our purpose, we included 19 items from only three dimensions: 7 items for General and Causal knowledge dimension (e.g., "The global CO2 concentration in the atmosphere has increased during the past 250 years" [True/False]), 6 items for Physical knowledge (e.g., "At the same quantity, $\mathrm{CO} 2$ is more harmful to the climate than methane" [True/False]), and 6 items for Consequence knowledge (e.g., "For the next few decades, the majority of climate scientists expect a warmer climate to increase the melting of polar ice, which will lead to an overall rise of the sea level" [True/False]). Participants scored 1 point per correct answer and a composite performance score was calculated (out of 19).

After answering each question, participants were instructed to indicate the extent to which they were confident that the response they just provided was the correct one, using a 
scale ranging from 0 (Not at all confident) to 100 (Totally confident $)^{2}$. Overconfidence levels were calculated as the difference between the average confidence level and the proportion of correct answers for each participant. An average confidence level higher than the proportion of correct answers indicates overconfidence, while an average confidence level lower than the proportion of correct answers indicates underconfidence (a difference of 0 indicates no confidence bias).

General Knowledge and Confidence: To assess participants' general knowledge, we used the measure proposed by Ilieva et al. (2018). The measure consists of 18 questions about general knowledge and participants have to decide between three options which is the correct one (e.g., "What artistic movement does Anacreontics belong to? » [Response options: Rococo; Romanticism; Realism]). Similar to the climate change literacy task, after answering each question, participants were instructed to indicate the extent to which they were confident in their answer, using a scale ranging from 0 (Not at all confident) to 100 (Totally confident).

\section{Results}

We computed Pearson's $r$ correlations and multiple linear regressions models. Including knowledge levels and overconfidence together made us suspect suppressor effects on the general knowledge variable (for which $r$ is nonsignificant and negative, but with a beta following multiple linear regressions significant and positive) and the climate change

\footnotetext{
${ }^{2}$ Some scholars use a confidence scale ranging from $33 \%$ (guess) to $100 \%$ (totally sure) when participants have to find the correct answer among 3 proposed options. However, because lay people are not necessarily comfortable with probabilities, and because we are interested in their subjective perception, we decided to range our confidence scale between 0 and 100. For the sake of completeness, we nevertheless reanalyzed our data excluding confidence ratings below $33 \%$. The results were straightforwardly the same as when all the confidence ratings were included in the analyses.
} 
overconfidence (for which $r$ is significant and positive, but with a beta following multiple linear regressions significant and negative). Because suppressor effects are hardly interpretable, we present two models enabling clearer interpretations, one which includes the knowledge variables (see Table 2a), one which includes the overconfidence variables (see Table 2b).

Cognitive sophistication was found to be an independent predictor of climate change skepticism $(\beta=-0.13)$. Importantly, in regard to our current purpose, climate change knowledge was the stronger, negative predictor of climate change skepticism $(\beta=-0.41)$ : people with greater knowledge about climate change were the less skeptical about climate change (note that this predictor was also significant, of the same sign, and was found the strongest predictor when explored using all the variables in a single model). Overconfidence, both at the general and specific level, although significantly associated with climate change skepticism in the bivariate correlations, did not survive the inclusion of the other variables, just as was the case for numeracy.

Table 2a. Semi-partial correlations and multiple regression results using climate change skepticism as the criterion (including general and climate change knowledge; Study 2).

\begin{tabular}{|c|c|c|c|c|c|c|c|c|}
\hline Predictor & $b$ & $\begin{array}{c}b \\
95 \% \mathrm{CI} \\
{[\mathrm{LL}, \mathrm{UL}]}\end{array}$ & beta & $\begin{array}{c}\text { beta } \\
95 \% \mathrm{CI} \\
{[\mathrm{LL}, \mathrm{UL}]}\end{array}$ & $s r^{2}$ & $\begin{array}{c}s r^{2} \\
95 \% \mathrm{CI} \\
{[\mathrm{LL}, \mathrm{UL}]}\end{array}$ & $r$ & Fit \\
\hline (Intercept) & $5.47 * *$ & {$[4.55,6.39]$} & & & & & & \\
\hline Age & $0.01 * *$ & {$[0.01,0.02]$} & 0.16 & {$[0.08,0.25]$} & .03 & {$[-.00, .05]$} & .10 & \\
\hline Gender & $-0.53 * *$ & {$[-0.74,-0.31]$} & -0.22 & {$[-0.31,-0.13]$} & .04 & {$[.01, .08]$} & $-.17 * *$ & \\
\hline Education & 0.03 & {$[-0.03,0.09]$} & 0.05 & {$[-0.04,0.14]$} & .00 & {$[-.01, .01]$} & .01 & \\
\hline Numeracy & -0.09 & {$[-0.39,0.21]$} & -0.03 & {$[-0.14,0.07]$} & .00 & {$[-.00, .01]$} & $-.19 * *$ & \\
\hline $\begin{array}{r}\text { Cognitive } \\
\text { Sophistication }\end{array}$ & $-1.11 *$ & {$[-2.01,-0.20]$} & -0.13 & {$[-0.24,-0.02]$} & .01 & {$[-.01, .03]$} & $-.24 * *$ & \\
\hline $\begin{array}{r}\text { General } \\
\text { Knowledge }\end{array}$ & 0.02 & {$[-0.02,0.07]$} & 0.05 & {$[-0.04,0.14]$} & .00 & {$[-.01, .01]$} & -.03 & \\
\hline $\begin{array}{r}\text { Climate Change } \\
\text { Knowledge }\end{array}$ & $-0.20 * *$ & {$[-0.24,-0.15]$} & -0.41 & {$[-0.51,-0.31]$} & .13 & {$[.07, .19]$} & $-.43 * *$ & \\
\hline & & & & & & & & $\begin{array}{l}R^{2}=.266^{* *} \\
95 \% \text { CI }[.18, .32]\end{array}$ \\
\hline
\end{tabular}


Note. A significant $b$-weight indicates the beta-weight and semi-partial correlation are also significant. $b$ represents unstandardized regression weights. beta indicates the standardized regression weights. $s r^{2}$ represents the semi-partial correlation squared. $r$ represents the zeroorder correlation. $L L$ and $U L$ indicate the lower and upper limits of a confidence interval, respectively.

$*$ indicates $p<.05 . * *$ indicates $p<.01$.

Table $2 b$. Semi-partial correlations and multiple regression results using climate change

skepticism as the criterion (including general and climate change overconfidence; Study 2).

\begin{tabular}{|c|c|c|c|c|c|c|c|c|}
\hline Predictor & $b$ & $\begin{array}{c}b \\
95 \% \mathrm{CI} \\
{[\mathrm{LL}, \mathrm{UL}]}\end{array}$ & beta & $\begin{array}{c}\text { beta } \\
95 \% \mathrm{CI} \\
{[\mathrm{LL}, \mathrm{UL}]}\end{array}$ & $s r^{2}$ & $\begin{array}{c}s r^{2} \\
95 \% \text { CI } \\
{[\mathrm{LL}, \mathrm{UL}]}\end{array}$ & $r$ & Fit \\
\hline (Intercept) & $3.97 * *$ & {$[3.18,4.76]$} & & & & & & \\
\hline Age & $0.01 *$ & {$[0.00,0.02]$} & 0.12 & {$[0.02,0.21]$} & .01 & {$[-.01, .03]$} & .06 & \\
\hline Gender & $-0.50 * *$ & {$[-0.73,-0.27]$} & -0.21 & {$[-0.30,-0.11]$} & .04 & {$[.00, .07]$} & $-.17 * *$ & \\
\hline Education & 0.02 & {$[-0.04,0.08]$} & 0.03 & {$[-0.07,0.12]$} & .00 & {$[-.00, .01]$} & .01 & \\
\hline Numeracy & -0.25 & {$[-0.56,0.06]$} & -0.09 & {$[-0.19,0.02]$} & .01 & {$[-.01, .02]$} & $-.19 * *$ & \\
\hline $\begin{array}{r}\text { Cognitive } \\
\text { Sophistication }\end{array}$ & $-2.15 * *$ & {$[-3.08,-1.21]$} & -0.25 & {$[-0.36,-0.14]$} & .04 & {$[.01, .08]$} & $-.26 * *$ & \\
\hline $\begin{array}{r}\text { General } \\
\text { overconfidence }\end{array}$ & 0.01 & {$[-0.00,0.01]$} & 0.08 & {$[-0.02,0.19]$} & .01 & {$[-.01, .02]$} & $.19 * *$ & \\
\hline $\begin{array}{l}\text { Climate change } \\
\text { overconfidence }\end{array}$ & 0.00 & {$[-0.00,0.01]$} & 0.04 & {$[-0.07,0.14]$} & .00 & {$[-.00, .01]$} & $.17^{* *}$ & \\
\hline & & & & & & & & $\begin{array}{l}R^{2}=.146^{* *} \\
95 \% \mathrm{CI}[.08, .20]\end{array}$ \\
\hline
\end{tabular}

Note. A significant $b$-weight indicates the beta-weight and semi-partial correlation are also significant. $b$ represents unstandardized regression weights. beta indicates the standardized regression weights. $s r^{2}$ represents the semi-partial correlation squared. $r$ represents the zeroorder correlation. $L L$ and $U L$ indicate the lower and upper limits of a confidence interval, respectively.

$*$ indicates $p<.05 . * *$ indicates $p<.01$.

The present results suggest that cognitive sophistication and climate change

knowledge are two independent negative predictors of climate change. So far, our results confirm one more time that cognitive reflection was a stronger predictor than cognitive ability. Of importance is that climate change knowledge was the stronger predictor of climate change skepticism. That is, cognitive sophistication seems not the unique central element 
predicting skepticism. Interestingly, these results highlight that both the structure and the content of the cognition are required to depict an acute understanding of the issue. These results go beyond the simple knowledge-deficit account (see Weber and Stern, 2011) or reasoning-deficit account, but stress that the both are critical aspects of climate understanding. Before drawing any further conclusion, we present a third study, whom purpose is twofold: first, it aims to replicate the present results; second, and of importance, it examines the articulation between knowledge/reasoning and political orientation, which has been shown to play an important part in the development of climate change skepticism.

\section{Study 3 Political orientation and climate change skepticism}

So far, our studies shed the light on the importance of cognitive reflection and climate change knowledge as leading factors of climate change skepticism. Beyond the implication of the cognitive dimension, there is also recent evidence that stances on climate change are predominantly shaped by political culture (e.g., McCright \& Dunlap, 2011; Gromet et al., 2013). Literature on motivated reasoning stresses that moral and political attitudes configure information processing and information selection strategy: when evaluating political arguments, people seem unable to escape the pull of political ideology (Jost et al., Lavine,2013: Taber \& Lodge, 2006). Strikingly, this Identity Protective Cognition (IPC; Kahan, 2015) seems not to be alleviated by evidence evaluation capabilities nor the extent of knowledge on a given topic (Kahan, 2017). In other words, critical reasoning aptitudes do not steer ideologically-motivated individuals toward the best possible evidence, unless the latter dovetails with ideological preferences (see Kahan, 2015). Worst, people high in critical reasoning and science comprehension were shown to have higher propensity to align their stance with that of their political group regarding the anthropogenic dimension of climate change (Kahan, 2015). Recent evidence suggests that, when it comes to gauging perceived 
risks associated with climate change, individualistic interests and partisan tribalism prevail while climate science comprehension and technical reasoning are instrumented to rationalize one's political preconception (Kahan et al., 2012). In context of climate change, IPC would predict that well-informed conservatists would act as potential opportunistic misinformers because of scientific consensus dismissal (Kahan, 2017). By contrast, even though their conclusions are in line with those of the scientific community, IPC would incline to see wellinformed liberals relying on the best available scientific evidence inasmuch as they match their political worldview.

To date, most of the investigations have been devoted to deciphering the reasons for identity-consistent positioning among conservatists. Some findings suggest that, beyond ideologically-driven disparity in exposure to climate science information (Campbell \& kay, 2014) or gap in attitude toward science (Gauchat, 2012), higher prevalence of climate change denialism among conservatists has to do with the fear that potential policy solutions - e.g., restriction on free-market, carbon taxes - conflict with their political values (Campbell \& kay, 2014).

This motivated analytic thinking is opposed to a classic view of analytic thinking (also referred to as bounded rationality), which proposes that analytic thinking supports sound reasoning (and the tendency to reject misinformation), independently of people's political identity (Pennycook \& Rand, 2019b; see also McPhetres, \& Pennycook, preprint). Recent data showed that analytic thinking promotes sound reasoning in many areas, with people more analytic showing decreased endorsement of fake news (e.g., Pennycook, \& Rand, 2017), conspiracy theories (e.g., Swami et al., 2014), and many other epistemically suspect beliefs (e.g., Pennycook et al., 2014a; Svedholm \& Lindeman, 2013; Trémolière \& Djeriouat, 2019); and it does so independently of cognitive ability (i.e., people's ease to correctly rely on the analytic system in the absence of a conflicting intuitive response). Data abound which support 
the classic view of analytic thinking. Lay people use an intuitive mode of thinking in the case of climatic change perception, relying mainly on simple mental models and experiential cues (Weber \& Stern, 2011). For instance, vivid experiences of climate change increase global climate change risk perception (Akerlof et al., 2013; Brody et al., 2008), while the lack of personal experience of climate change leads to call into question the perceived seriousness and the anthropogenic roots of the phenomenon (see Spence et al., 2011).

In this study, we appraise dispositional cognitive factors, knowledge and knowledge overconfidence, and political orientation. Two competing predictions can be made regarding the influence of these variables as a function of political orientation. One the one hand, IPC would allow to conjecture a polarization effect in which high reasoning proficiency, higher level of knowledge, and lower level of knowledge overconfidence would be associated with lower levels of climate change skepticism among liberals whereas these elements would reinforce climate change skepticism among conservatives. On the other hand, the classic view of analytical thinking would predict that these elements would contribute to abate climate change skepticism irrespective of political partisanship. Overall, the planned exploration will provide additional insights in the attempt to disentangle the influence of both cognitive and cultural dimensions.

\section{Method}

Sampling rationale: An a priori power analysis was conducted using Gpower (Erdfelder et al., 1996). The analysis indicated that a sample size of 251 would be required to reach a significant effect of our predictors with a power of $95 \%$ and an alpha of 0.05 , based on medium effect size $\left(\mathrm{F}^{2}\right)$ of 0.10 . Based on prior studies, we expected that between hundred and hundred and fifty participants would be discarded from the sample due to attention check failure. 
Participants and design: A total of 397 American participants were recruited on the Amazon Mechanical Turk online data collection platform. Among the initial sample, 125 participants did not complete the questionnaire and or failed to correctly answer the attention check question. They were then removed from any further analysis, leaving a final sample of 272 participants $\left(97\right.$ females; $\left.\mathrm{Mean}_{\mathrm{age}}=37.6, \mathrm{SD}_{\mathrm{age}}=12.1\right)($ see supplementary material $\mathrm{S} 1 \mathrm{c}$ for detailed demographic information).

\section{Material:}

The climate change skepticism scale (Cronbach's $\alpha=.94$ ), the cognitive reflection measure (CRT), the cognitive ability measure (Numeracy), the general knowledge (and confidence) and the climate change knowledge (and confidence) measures were the same as the ones used in Study 2. The novelty is the assessment of political orientation. We used the scale used by Pennycook et al. (2020) which consists in the two following statements "on social issues, I am" and "on economic issues, I am" to which participants are instructed to answer using a 5point scale ranging from 1 (Strongly liberal) to 5 (Strongly conservative). The questions showed very good reliability $(\alpha=.85)$, and a composite mean score was computed.

\section{Results}

Before conducting our main analyses, we started by addressing a current worry about the political representativeness of participants recruited on MTurk (e.g., Kahan, 2013; but see Clifford et al., 2015, for a direct assessment; see also Berinsky et al., 2012; Mullinix et al., 2015, for instance, who show that Mturkers are at least -if no more- as representative of the U.S. population as in-person convenience samples). As it is displayed in Figure 1, we observe a widespread distribution, with data not normally distributed $(p<.001)$ and negatively skewed (skewness $=-0.61$ ), suggesting that conservatives are sufficiently represented to carry out analyses. 


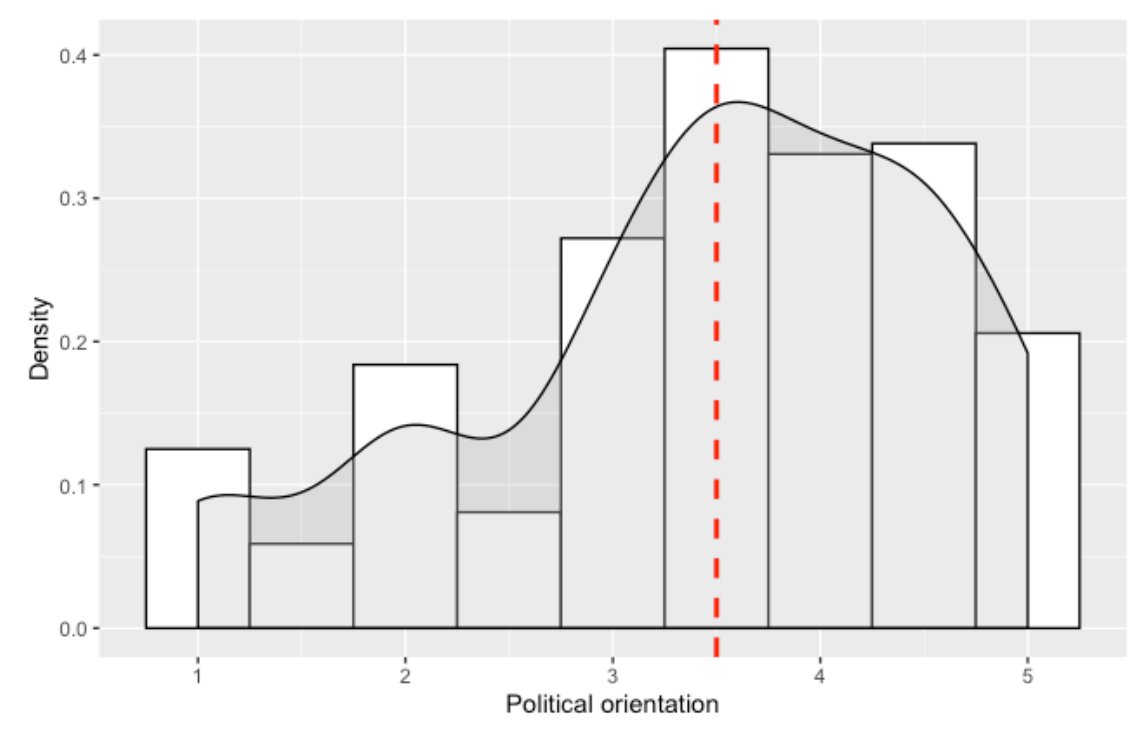

Figure 1. Frequency and density of the sample on the political orientation variable, ranging from 1 (Liberal) to 5 (Conservative) (Study 3).

Similar to Study 2, an initial investigation of the regressed variable including all our variables of interest led us to suspect a suppression effect for the general knowledge variable (which has a significant and negative correlation coefficient, but a significant and positive beta following multiple linear regressions). Following the same rationale as in Study 2, we present two models, one which includes the knowledge variables (see Table 3a), and one which includes the overconfidence variables (see Table 3b).

CRT $(\beta=-0.17)$ and climate change knowledge $(\beta=-0.33)$ remained significant negative predictors of climate change skepticism. Overconfidence, both at the general and specific levels, remained significant when including the other variables $\left(\beta_{\text {general }}=0.13\right.$; $\left(\beta_{\text {specific }}=0.27\right)$. Of importance, with regard to our current purpose, is the politics variable, which was found the greater predictor of climate change skepticism $(\beta=0.36)$ with participants more conservative showing the highest levels of climate change skepticism; and it was observed in the two models. 
Table 3a. Semi-partial correlations and multiple regression results using climate change skepticism as the criterion (including general and climate change knowledge; Study 3 ).

\begin{tabular}{|c|c|c|c|c|c|c|c|}
\hline Predictor & $b$ & $\begin{array}{c}b \\
95 \% \text { CI } \\
{[\mathrm{LL}, \mathrm{UL}]}\end{array}$ & beta & $\begin{array}{c}\text { beta } \\
95 \% \text { CI } \\
{[\mathrm{LL}, \mathrm{UL}]}\end{array}$ & $s r^{2}$ & $\begin{array}{c}s r^{2} \\
95 \% \text { CI } \\
{[\mathrm{LL}, \mathrm{UL}]}\end{array}$ & $r$ \\
\hline (Intercept) & $4.19 * *$ & {$[3.35,5.04]$} & & & & & \\
\hline Age & -0.00 & {$[-0.01,0.01]$} & -0.00 & {$[-0.09,0.09]$} & .00 & {$[-.00, .00]$} & -.11 \\
\hline Gender & $-0.26^{* *}$ & {$[-0.43,-0.10]$} & -0.13 & {$[-0.22,-0.05]$} & .02 & {$[-.00, .04]$} & $-.16^{* *}$ \\
\hline Education & 0.06 & {$[-0.01,0.13]$} & 0.07 & {$[-0.01,0.16]$} & .00 & {$[-.01, .02]$} & .11 \\
\hline Numeracy & $-0.34^{*}$ & {$[-0.64,-0.03]$} & -0.12 & {$[-0.22,-0.01]$} & .01 & {$[-.01, .02]$} & $-.42 * *$ \\
\hline CRT & $-0.60 * *$ & {$[-0.96,-0.23]$} & -0.17 & {$[-0.27,-0.07]$} & .02 & {$[-.00, .04]$} & $-.45 * *$ \\
\hline $\begin{array}{r}\text { General } \\
\text { knowledge }\end{array}$ & -0.02 & {$[-0.49,0.45]$} & -0.00 & {$[-0.09,0.09]$} & .00 & {$[-.00, .00]$} & $-.14^{*}$ \\
\hline $\begin{array}{l}\text { Climate change } \\
\text { knowledge }\end{array}$ & $-2.65 * *$ & {$[-3.43,-1.87]$} & -0.33 & {$[-0.42,-0.23]$} & .08 & {$[.03, .13]$} & $-.54 * *$ \\
\hline Politics & $0.31 * *$ & {$[0.24,0.39]$} & 0.36 & {$[0.27,0.45]$} & .11 & {$[.06, .17]$} & $.54 * *$ \\
\hline
\end{tabular}

Note. A significant $b$-weight indicates the beta-weight and semi-partial correlation are also significant. $b$ represents unstandardized regression weights. beta indicates the standardized regression weights. $s r^{2}$ represents the semi-partial correlation squared. $r$ represents the zeroorder correlation. $L L$ and $U L$ indicate the lower and upper limits of a confidence interval, respectively.

$*$ indicates $p<.05 . * *$ indicates $p<.01$.

Table $3 b$. Semi-partial correlations and multiple regression results using climate change skepticism as the criterion (including general and climate change overconfidence; Study 3).

\begin{tabular}{|c|c|c|c|c|c|c|c|c|}
\hline Predictor & $b$ & $\begin{array}{c}b \\
95 \% \mathrm{CI} \\
{[\mathrm{LL}, \mathrm{UL}]}\end{array}$ & beta & $\begin{array}{c}\text { beta } \\
95 \% \text { CI } \\
{[\mathrm{LL}, \mathrm{UL}]}\end{array}$ & $s r^{2}$ & $\begin{array}{c}s r^{2} \\
95 \% \mathrm{CI} \\
{[\mathrm{LL}, \mathrm{UL}]}\end{array}$ & $r$ & Fit \\
\hline (Intercept) & $2.45^{* *}$ & {$[1.70,3.19]$} & & & & & & \\
\hline Age & -0.00 & {$[-0.01,0.00]$} & -0.03 & {$[-0.12,0.06]$} & .00 & {$[-.00, .01]$} & -.11 & \\
\hline Gender & $-0.21 *$ & {$[-0.38,-0.04]$} & -0.10 & {$[-0.19,-0.02]$} & .01 & {$[-.01, .03]$} & $-.16^{* *}$ & \\
\hline Education & 0.05 & {$[-0.02,0.12]$} & 0.06 & {$[-0.02,0.15]$} & .00 & {$[-.01, .01]$} & .11 & \\
\hline Numeracy & -0.28 & {$[-0.57,0.02]$} & -0.10 & {$[-0.20,0.01]$} & .01 & {$[-.01, .02]$} & $-.42 * *$ & \\
\hline CRT & $-0.68^{* * *}$ & {$[-1.03,-0.33]$} & -0.19 & {$[-0.29,-0.09]$} & .03 & {$[-.00, .05]$} & $-.45^{* *}$ & \\
\hline $\begin{array}{r}\text { General } \\
\text { overconfidence }\end{array}$ & $0.01^{*}$ & {$[0.00,0.01]$} & 0.13 & {$[0.02,0.23]$} & .01 & {$[-.01, .03]$} & $.45^{* *}$ & \\
\hline $\begin{array}{l}\text { Climate change } \\
\text { overconfidence }\end{array}$ & $0.01^{* *}$ & {$[0.01,0.02]$} & 0.27 & {$[0.17,0.37]$} & .05 & {$[.01, .08]$} & $.56^{* *}$ & \\
\hline Politics & $0.28 * *$ & {$[0.20,0.36]$} & 0.32 & {$[0.23,0.41]$} & .08 & {$[.04, .13]$} & $.54 * *$ & $38 * *$ \\
\hline
\end{tabular}


Note. A significant $b$-weight indicates the beta-weight and semi-partial correlation are also significant. $b$ represents unstandardized regression weights. beta indicates the standardized regression weights. $s r^{2}$ represents the semi-partial correlation squared. $r$ represents the zeroorder correlation. $L L$ and $U L$ indicate the lower and upper limits of a confidence interval, respectively.

$*$ indicates $p<.05 . * *$ indicates $p<.01$.

We further tested whether the relationship between our cognitive variables and climate change skepticism varied as a function of political orientation. To this end, we classified participants who scored 1 or 2 on the political orientation scale as Liberals, participants who scored 3 as Moderates, and participants who scored 4 or 5 as Conservatives (see Pennycook et al. (2020). Interaction analyses were performed between the cognitive variables and the political orientation variable (dummy coded). All the interactions, but for the Numeracy $\times$ Political orientation, were significant (Table 4; see also Figure 2).

Table 4. Results from the interaction analyses. Political orientation was dummy coded. All the combinations were tested before concluding on non-significant interactions.

\begin{tabular}{|c|c|c|c|c|c|}
\hline & Estimate & SE & $t$ & $p$ & Interaction \\
\hline CRT x Politics (Moderate) & -0.2897 & 0.5118 & -0.566 & 0.57 & \multirow{2}{*}{$\operatorname{sig}$} \\
\hline CRT x Politics (Conservative) & 0.9406 & 0.3799 & 2.476 & $0.01 *$ & \\
\hline Numeracy x Politics (Moderate) & 0.2748 & 0.4618 & 0.595 & 0.55 & \multirow{2}{*}{ NS } \\
\hline Numeracy x Politics (Conservative) & 0.5398 & 0.3449 & 1.565 & 0.12 & \\
\hline General knowledge $\mathrm{x}$ Politics (Moderate) & 2.0919 & 0.9480 & 2.207 & $0.03 *$ & \multirow{2}{*}{ sig } \\
\hline General knowledge x Politics (Conservative) & 0.6363 & 0.6961 & 0.914 & 0.36 & \\
\hline Climate change knowledge $\mathrm{x}$ Politics (Moderate) & -0.1680 & 1.0857 & -0.155 & 0.88 & \multirow{2}{*}{$\operatorname{sig}$} \\
\hline Climate change knowledge x Politics (Conservative) & 2.5590 & 0.8412 & 3.042 & $0.003 * *$ & \\
\hline General overconfidence x Politics (Moderate) & 0.023274 & 0.008756 & 2.658 & $0.008 * *$ & \multirow{2}{*}{ sig } \\
\hline General overconfidence x Politics (Conservative) & 0.008466 & 0.007919 & 1.069 & 0.29 & \\
\hline Climate change overconfidence $\mathrm{x}$ Politics (Moderate & 0.002897 & 0.008287 & 0.350 & 0.73 & \multirow[b]{2}{*}{ sig } \\
\hline $\begin{array}{l}\text { Climate change overconfidence x Politics (Conserva- } \\
\text { tive) }\end{array}$ & -0.012351 & 0.005755 & -2.146 & $0.03 *$ & \\
\hline
\end{tabular}


Simple slopes analyses were performed (all adjusted using Tukey method), testing independently how much the slope for each of the variables who independently predicted climate change skepticism (cognitive reflection, climate change knowledge, and climate change overconfidence) differed as a function of political orientation (Liberal, Moderate, or Conservative). Regarding CRT, the slope among conservatives was significantly flatter than that of the liberals (estimate $=-0.94, \mathrm{SE}=0.38, t(266)=-2.48, p=0.04)$ and the moderates (estimate $=-1.23, \mathrm{SE}=0.48, t(266)=-2.57, p=0.03)$, while no difference was observed between liberals and moderates (estimate $=0.29, \mathrm{SE}=0.51, t(266)=0.57, p=0.84)$. The same pattern of results was observed for climate change knowledge: conservatives significantly differed from moderates (estimate $=-2.73, \mathrm{SE}=1.08, t(266)=-2.52, p=0.02$ ) and liberals (estimate $=-2.56, \mathrm{SE}=0.84, t(266)=-3.04, p=0.007$ ), with flatter slopes for the conservative group, while no difference was observed between liberals and moderates (estimate $=0.17, \mathrm{SE}=1.08, t(266)=0.16, p=0.99$. Climate change overconfidence followed the same direction, although the differences did not reach significance (all $p \mathrm{~s}>.08$ ). Taken together, these results suggest that the cognitive variables predict significantly less climate change skepticism in conservatives. 

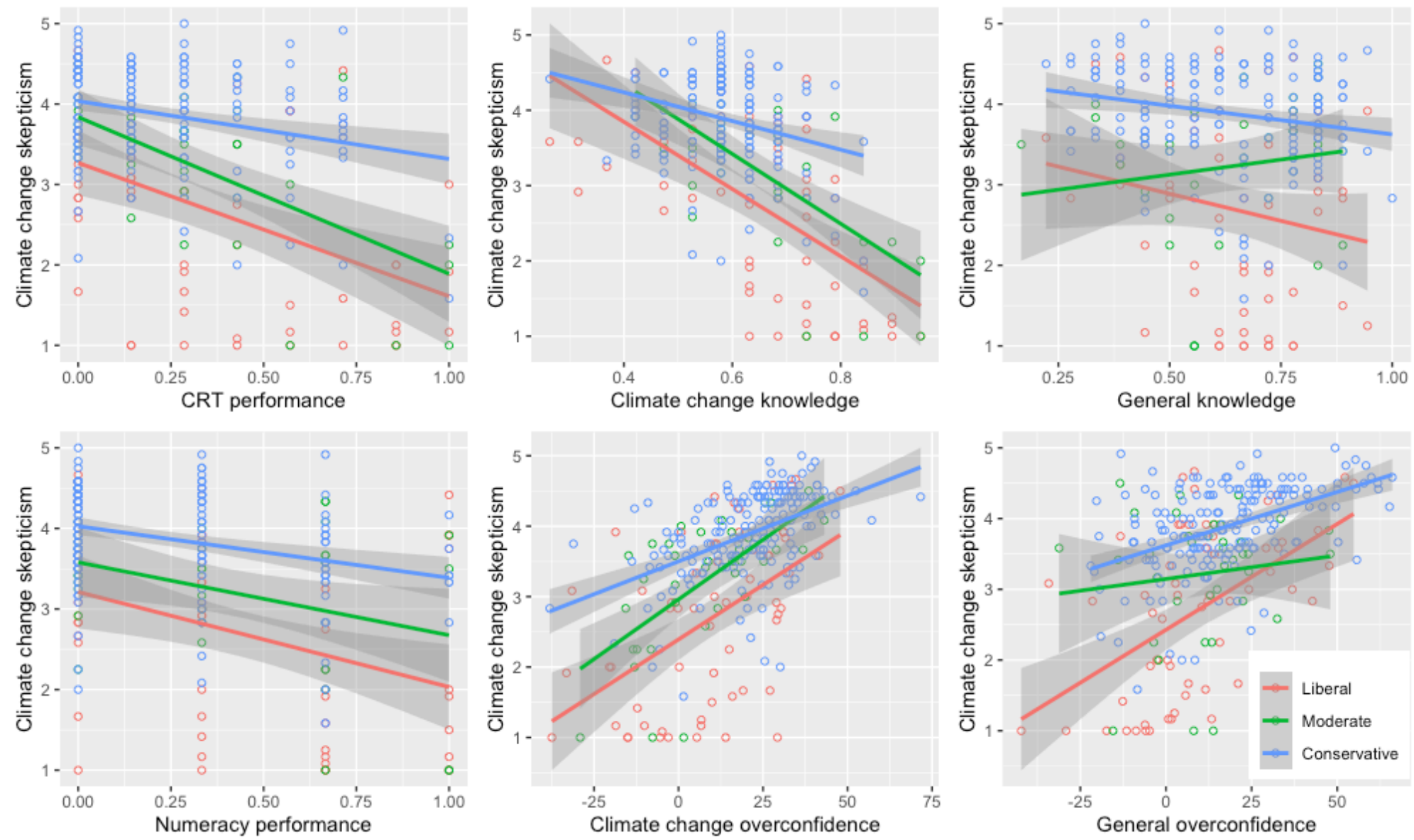

Figure 2. Interaction patterns between Political orientation (Liberals, Moderates, Conservatives) and each of our six main variables in predicting climate change.

\section{General discussion}

Despite scientific evidence and consensus, some people remain skeptical about the causes or else the existence of climate change, justifying further investigations of the underlying psychological processes. We tested a recent paradigm based on cognitive reflection (or more broadly cognitive sophistication), and we observed that people more analytic were less skeptical about climate change than people more intuitive, regardless of their cognitive ability or science literacy (Study 1). Specific knowledge (here, about climate change) was also observed to be an independent negative predictor of climate change, together with cognitive sophistication (Study 2). The influential value of these cognitive 
variables in explaining climate change skepticism varied according to political orientation (Study 3). Specifically, cognitive reflection, climate change knowledge and specific overconfidence were less associated with endorsement of climate change skepticism among conservatives than among liberals and moderates (note that these differences were only marginal to nonsignificant for specific overconfidence).

Taken together, these findings support the notion that climate change skepticism can be shaped by people's information-processing style, their amount of knowledge about the topic, and their accuracy in assessing their specific knowledge. Interestingly, classical reasoning proponents argue that analytical thinking is not always sufficient, and that mastering climate models may also be required to accurately understand the anthropogenic underpinning of climate change (see Pennycook \& Rand, 2019). Consistent with the conclusions by McPhetres and Pennycook (preprint) about people's beliefs about science, we observed that specific knowledge (here in the domain of climate change) was the best predictor of climate change skepticism. In this respect, reasoning processing and self-insight into the understanding of basic climate science have consequences on beliefs in climate change.

Interestingly, we also observed, in Study 3, that overconfidence in domain-specific knowledge independently predicts climate change skepticism (although that variable did not resist the other predictors in Study 2). Overall, participants who showed higher levels of epistemic circumspection exhibited lower levels of climate change skepticism. In line with our expectation, aside of cognitive structure and knowledge levels, the metacognitive dimension may be of great importance in the process. Hence, intellectual humility and circumspection could help facilitate the recognition of the inherent complexity of climate science or refrain one from jumping to hasty conclusion. 
The present results do not support IPC and the proposed dynamic between ideological orientation and cognitive factors in the domain of climate change evaluation (see Kahan et al., 2012, Kahan, 2015). Our results showed that both cognitive reflection and the amount of knowledge on the topic negatively predict climate change anti-skepticism in liberals. The predictive value of these variables was significantly weaker in conservatives but remained of the same direction: cognitive reflection and knowledge negatively predict climate change skepticism in conservatives, contrary to what IPC would have suggested (Kahan, 2017). The results reported herein would align with the classical reasoning account, also they do not provide full support for a pure version of this account, at least in this specific context: the propensity to rely on an analytic thinking style prevent liberals and conservatives from exhibiting climate change skepticism, but this effect is reduced in conservatives, as supported by the interaction effects and the subsequent simple slope analyses..

Reflecting upon the results observed in Study 3, another perspective may be advocated. The pattern of relationships between the cognitive variables (especially cognitive reflection and domain-specific knowledge about climate) and climate change skepticism in the liberal subsample mirrors that of the conservative subsample, but with a different magnitude. An asymmetrical conflict account may help reconcile both the classical reasoning and the IPC perspectives about the effect of analytical thinking on the topic of climate change. According to this perspective, when it comes to reflect about the existence of climate change or its anthropogenic nature, analytical conservatives could undergo a taxing transaction between their motivation and ability for analytic thinking and their identity-protective mindset; this conflict would not be experienced by analytical liberals, because the rational and evidence-based conclusions dovetail with partisan narratives about the issue. If analytical conservatives were to deliberately ignore the best available scientific evidence in favor of partisan tribalism we would observe, if not a positive correlation between cognitive 
reflection/climate knowledge and climate change skepticism (according to an IPC conjecture), at least an absence of correlation. In the same manner, if a deliberative mindset remains the exclusive explanatory system, we would not observe that the effects of cognitive variables are partly shaped by political orientation. Everything happened as if conservatives who are cognitively equipped to grasp the stake of climate change showed moderation of their skepticism without completely giving it up. According to this asymmetrical conflict account, the opposite trend would be expected if a scientific consensus would turn out to be favorable to a conservative worldview.

However, things are not as simple as it would appear since conservatives have been shown in the literature to be more concerned by the concept of authority/respect than liberals (Graham et al., 2009). Perhaps, analytical liberals would go through a less demanding conflicting experience. Future research is needed to examine whether such a conflict exists more in the conservative group. In addition, it would be highly interesting to study the narrative and the reasoning of individuals who portray themselves as conservatives but hold counter-normative stance about the question of climate change. It is reasonable enough to state that among the conservative population, some people, with science background or not, rely on scientific consensus and are convinced that climate change is actually happening.

How can one success at debiasing climate change skeptics? There is no obvious answer and several propositions and attempts have been made, most that target the intuitive component. In response to the observation that lay people are ready to conform their beliefs to that of their home group, a call has recently been made for climate communicators to create a sound climate change message in which scientific information does not threaten groups' values (Kahan et al., 2012), as well as for communicators to make people they want to convince like them (Haidt, 2012). Taking people's difficulty to apprehend climate change into account, other levers have been proposed that rely on climate change nudges (Thaler and 
Sunstein, 2008). As promising they are, they only show mixed effects to date, reliance on nudges undermining support for more costly greater impact policies (Hagmann et al., 2019).

We contend that targeting the individuals' intuitive side is not sufficient on its own in the long run, as people's deliberative engagement seems to us a sinequanone condition for fostering the conditions for a march towards informed and sustainable environmental improvement. Although it is largely indirect, we conducted additional analyses including education level, which showed that education never independently predicted climate change skepticism. This suggests that specific levers must actually be targeted. We believe that parallel efforts must be made to promote critical thinking in education and foster intellectual humility (see Pithers, \& Soden, 2000). Inoculation framework has proven useful to promote critical thinking in the case of climate change, by giving people information that counters misinformation, and by educating them on how to examine fallacious reasoning (Cook et al., 2017). Intellectual humility, on his side, has been shown to be connected to critical thinking and learning. It qualifies as a worthy and meaningful educational purpose (Baehr, 2016) as people might lack self-insight about the foundation of their opinion and beliefs (Fernbach et al., 2013). In this respect, education can take place everywhere. Encouraging results have been observed through recent popular initiatives in which simple informal dialogue was designed to make people dialectically tackle their questionable beliefs. Inspired by Socrates' maieutic philosophy in which people come to probe the foundation of their opinion, street epistemology (Boghossian, 2014) is a step by step discussion that has proven useful (see also Ranney \& Clark, 2016, on the role of learning and instructions on understanding of climate change). Such educational initiatives must not only target lay people, but also leaders who exert important vertical influence (Druckman \& McGrath, 2019). A partisan shift or moderation regarding climate change issue could help reducing potential culture-versuscognition conflicts among analytical conservatives. 
The road to the global acceptation of climate change and human responsibility in the process is full of pitfalls. Maintaining higher educational standards is not a sufficient condition to address the biggest problem humanity have to solve. It is not the quantity of information that is at stake, but how people process information and how they practice intellectual self-defense or epistemic vigilance (Sperber et al., 2010) in a world overwhelmingly filled with fake news and ideological discourse.

\section{Author contributions}

The authors contributed equally at all stages of the present research.

\section{Competing interests}

The authors declare no competing interests.

\section{Acknowledgment}

This study received support from the LABEX CORTEX (ANR-11-LABX-0042) of Université de Lyon, within the program "Investissements d'Avenir" (ANR-11-IDEX-0007) operated by the French National Research Agency (ANR). 


\section{References}

Akerlof, K., Maibach, E. W., Fitzgerald, D., Cedeno, A. Y., \& Neuman, A. (2013). Do people “personally experience" global warming, and if so how, and does it matter? Global Environmental Change, 23(1), 81-91.

Allum, N., Sturgis, P., Tabourazi, D., \& Brunton-Smith, I. (2008). Science knowledge and attitudes across cultures: A meta-analysis. Public understanding of science, 17(1), 3554.

Anderegg, W. R. (2010). Moving beyond scientific agreement. Climatic Change, 101(3), 331337.

Baehr, J. (2016). Is intellectual character growth a realistic educational aim? Journal of Moral Education, 45, 117-131.

Baron, J., Scott, S., Fincher, K., \& Metz, S. E. (2015). Why does the cognitive reflection test (sometimes) predict utilitarian moral judgment (and other things)? Journal of Applied Research in Memory and Cognition, 4(3), 265-284.

Bedford, D., \& Cook, J. (2013). Agnotology, scientific consensus, and the teaching and learning of climate change: A response to Legates, Soon and Briggs. Science \& Education, 22(8), 2019-2030.

Berinsky, A. J., Huber, G. A., \& Lenz, G. S. (2012). Evaluating online labor markets for experimental research: Amazon. com's Mechanical Turk. Political analysis, 20(3), 351368.

Berry, W. D., Feldman, S., \& Stanley Feldman, D. (1985). Multiple regression in practice (No. 50). Sage.

Boghossian, P. (2014). A manual for creating atheists. Pitchstone Publishing (US\&CA). 
Brody, S. D., Zahran, S., Vedlitz, A., \& Grover, H. (2008). Examining the relationship between physical vulnerability and public perceptions of global climate change in the United States. Environment and behavior, 40(1), 72-95.

Cacioppo, J. T., \& Petty, R. E. (1982). The need for cognition. Journal of Personality and Social Psychology, 42, 116-131.

Campbell, T. H., \& Kay, A. C. (2014). Solution aversion: On the relation between ideology and motivated disbelief. Journal of personality and social psychology, 107, 809-824.

Clifford, S., Jewell, R. M., \& Waggoner, P. D. (2015). Are samples drawn from Mechanical Turk valid for research on political ideology? Research \& Politics, 2(4), 2053168015622072.

Cook, J., Lewandowsky, S., \& Ecker, U. K. (2017). Neutralizing misinformation through inoculation: Exposing misleading argumentation techniques reduces their influence. PloS one, 12(5), $\mathrm{e} 0175799$.

De Neys, W. (2014). Conflict detection, dual processes, and logical intuitions: Some clarifications. Thinking \& Reasoning, 20, 169-187.

Druckman, J. N., \& McGrath, M. C. (2019). The evidence for motivated reasoning in climate change preference formation. Nature Climate Change, 9, 111-119.

Ehrlich, P. R. (1996). Environmental anti-science. Trends in ecology \& evolution, 11(9), 393.

Ejelöv, E., Hansla, A., Bergquist, M., \& Nilsson, A. (2018). Regulating emotional responses to climate change-a construal level perspective. Frontiers in psychology, 9, 629.

Epstein, S. (1994). Integration of the cognitive and psychodynamic unconscious. American Psychologist, 49, 709-724. 
Epstein, S., Lipson, A., Holstein, C., \& Huh, E. (1992). Irrational reactions to negative outcomes: Evidence for two conceptual systems. Journal of Personality and Social Psychology, 62(2), 328-339.

Epstein, S., Pacini, R., Denes-Raj, V., \& Heier, H. (1996). Individual differences in intuitiveexperiential and analytical-rational thinking styles. Journal of Personality and Social Psychology, 71(2), 390-405.

Erdfelder, E., Faul, F., \& Buchner, A. (1996). Gpower: A general power analysis program. Behavior Research Methods, Instruments, \& Computers, 28(1), 1-11.

Evans, J. S. B. T., \& Stanovich, K. E. (2013). Dual-process theories of higher cognition: Advancing the debate. Perspectives on Psychological Science, 8(3), 223-241.

Farias, M., Newheiser, A. K., Kahane, G., \& de Toledo, Z. (2013). Scientific faith: Belief in science increases in the face of stress and existential anxiety. Journal of experimental social psychology, 49(6), 1210-1213.

Fernbach, P. M., Rogers, T., Fox, C. R., \& Sloman, S. A. (2013). Political extremism is supported by an illusion of understanding. Psychological science, 24(6), 939-946.

Frederick, S. (2005). Cognitive reflection and decision-making. Journal of Economic Perspectives, 19(4), 25-42.

Gauchat, G. (2012). Politicization of science in the public sphere: A study of public trust in the United States, 1974 to 2010. American Sociological Review, 77,167-187.

Graham, J., Haidt, J., \& Nosek, B. A. (2009). Liberals and conservatives rely on different sets of moral foundations. Journal of personality and social psychology, 96(5), 1029.

Gromet, D. M., Kunreuther, H., \& Larrick, R. P. (2013). Political ideology affects energyefficiency attitudes and choices. Proceedings of the National Academy of Sciences, $110(23), 9314-9319$. 
Hagmann, D., Ho, E. H., \& Loewenstein, G. (2019). Nudging out support for a carbon tax. Nature Climate Change, 1.

Haidt, J. (2012). The righteous mind: Why good people are divided by politics and religion. Vintage.

Hamilton, L. C., Hartter, J., \& Saito, K. (2015). Trust in scientists on climate change and vaccines. Sage Open, 5(3), 2158244015602752.

Hart, W., Albarracín, D., Eagly, A. H., Brechan, I., Lindberg, M. J., \& Merrill, L. (2009). Feeling validated versus being correct: a meta-analysis of selective exposure to information. Psychological bulletin, 135(4), 555.

Hoppe, E. I., \& Kusterer, D. J. (2011). Behavioral biases and cognitive reflection. Economics Letters, 110(2), 97-100.

Ilieva, V., Brudermann, T., \& Drakulevski, L. (2018). "Yes, we know!” (Over) confidence in general knowledge among Austrian entrepreneurs. PloS one, 13(5), e0197085.

Jacques, P. J., Dunlap, R. E., \& Freeman, M. (2008). The organisation of denial: Conservative think tanks and environmental scepticism. Environmental politics, 17(3), 349-385.

Jost, J. T., Hennes, E. P., \& Lavine, H. (2013). “Hot” political cognition: Its self-, group-, and system-serving purposes. In D. E. Carlson (Ed.), Oxford handbook of social cognition (pp. 851-875). New York, NY: Oxford University Press.

Kahan, D. M. (2013). What's a "valid” sample? Problems with Mechanical Turk study samples, part 1. Cultural Cognition Project Blog. Available at: http://www.culturalcognition.net/blog/2013/7/8/whats-a-valid-sample-problems-withmechanical-turk-study-sam.html.

Kahan, D. M. (2015). The politically motivated reasoning paradigm, part 1: What politically motivated reasoning is and how to measure it. Emerging trends in the social and behavioral sciences: An interdisciplinary, searchable, and linkable resource, 1-16. 
Kahan, D. M., Peters, E., Dawson, E. C., \& Slovic, P. (2017). Motivated numeracy and enlightened self-government. Behavioural Public Policy, 1(1), 54-86.

Kahan, D. M., Peters, E., Wittlin, M., Slovic, P., Ouellette, L. L., Braman, D., \& Mandel, G. (2012). The polarizing impact of science literacy and numeracy on perceived climate change risks. Nature climate change, 2(10), 732.

Kahneman, D. (2011). Thinking, fast and slow. New York, NY: Farrar, Straus \& Giroux.

Kellstedt, P. M., Zahran, S., \& Vedlitz, A. (2008). Personal efficacy, the information environment, and attitudes toward global warming and climate change in the United States. Risk Analysis: An International Journal, 28(1), 113-126.

Kruger, J., \& Dunning, D. (1999). Unskilled and unaware of it: how difficulties in recognizing one's own incompetence lead to inflated self-assessments. Journal of personality and social psychology, 77(6), 1121.

Leiserowitz, A. A., Maibach, E. W., Roser-Renouf, C., Smith, N., \& Dawson, E. (2013). Climategate, public opinion, and the loss of trust. American behavioral scientist, 57(6), 818-837.

Liberali, J. M., Reyna, V. F., Furlan, S., Stein, L. M., \& Pardo, S. T. (2012). Individual differences in numeracy and cognitive reflection, with implications for biases and fallacies in probability judgment. Journal of Behavioral Decision Making, 25(4), 361381.

Malka, A., Krosnick, J. A., \& Langer, G. (2009). The association of knowledge with concern about global warming: Trusted information sources shape public thinking. Risk Analysis: An International Journal, 29(5), 633-647.

McCright, A. M., \& Dunlap, R. E. (2011). Cool dudes: The denial of climate change among conservative white males in the United States. Global environmental change, 21(4), 1163-1172. 
McPhetres, J., \& Pennycook, G. (preprint). Science beliefs, political ideology, and cognitive sophistication. https://doi.org/10.31219/osf.io/ad9v7

McPhetres, J., Rutjens, B. T., Weinstein, N., \& Brisson, J. A. (2019). Modifying attitudes about modified foods: increased knowledge leads to more positive attitudes. Journal of Environmental Psychology, 64, 21-29.

National Science Board. Science and Engineering Indicators, 2010. (National Science Foundation, Arlington, Va., 2010).

Milfont, T. L. (2012). The interplay between knowledge, perceived efficacy, and concern about global warming and climate change: a one-year longitudinal study. Risk Analysis: An International Journal, 32(6), 1003-1020.

Milfont, T. L., Milojev, P., Greaves, L. M., \& Sibley, C. G. (2015). Socio-structural and psychological foundations of climate change beliefs. New Zealand Journal of Psychology, 44(1).

Miton, H., \& Mercier, H. (2015). Cognitive obstacles to pro-vaccination beliefs. Trends in Cognitive Sciences, 19(11), 633-636.

Mullinix, K. J., Leeper, T. J., Druckman, J. N., \& Freese, J. (2015). The generalizability of survey experiments. Journal of Experimental Political Science, 2(2), 109-138.

Nsce (2012). NCSE Tackles Climate Change Denial. Retrieved from https://ncse.ngo/ncsetackles-climate-change-denial-0

Oreskes, N. (2005). The scientific consensus on climate change. Science, 307, 355-355.

Pennycook, G., Cheyne, J. A., Barr, N., Koehler, D. J., \& Fugelsang, J. A. (2014b). The role of analytic thinking in moral judgements and values. Thinking \& Reasoning, 20(2), $188-214$

Pennycook, G., Fugelsang, J. A., \& Koehler, D. J. (2015). Everyday consequences of analytic thinking. Current Directions in Psychological Science, 24(6), 425-432. 
Pennycook, G., McPhetres, J., Bago, B., \& Rand, D. (2020). Predictors of attitudes and misperceptions about COVID-19 in Canada, the UK, and the USA. Preprint

Pennycook, G., \& Rand, D. G. (2017). Who falls for fake news? The roles of analytic thinking, motivated reasoning, political ideology, and bullshit receptivity. SSRN Electronic Journal.

Pithers, R. T., \& Soden, R. (2000). Critical thinking in education: A review. Educational research, 42(3), 237-249.

Plutzer, E., McCaffrey, M., Hannah, A. L., Rosenau, J., Berbeco, M., \& Reid, A. H. (2016). Climate confusion among US teachers. Science, 351(6274), 664-665.

Ranney, M. A., \& Clark, D. (2016). Climate change conceptual change: Scientific information can transform attitudes. Topics in Cognitive Science, 8(1), 49-75.

Reynolds, T. W., Bostrom, A., Read, D., \& Morgan, M. G. (2010). Now what do people know about global climate change? Survey studies of educated laypeople. Risk Analysis: An International Journal, 30(10), 1520-1538.

Rutjens, B. T., Heine, S. J., Sutton, R. M., \& van Harreveld, F. (2018). Attitudes towards science. In Advances in Experimental Social Psychology (Vol. 57, pp. 125-165). Academic Press.

Schuldt, J. P., Konrath, S. H., \& Schwarz, N. (2011). "Global warming” or “climate change”? Whether the planet is warming depends on question wording. Public Opinion Quarterly, $75(1), 115-124$.

Schwartz, L. M., Woloshin, S., Black, W. C., \& Welch, H. G. (1997). The role of numeracy in understanding the benefit of screening mammography. Annals of Internal Medicine, 127(11), 966-972.

Spence, A., Poortinga, W., Butler, C., \& Pidgeon, N. F. (2011). Perceptions of climate change 
and willingness to save energy related to flood experience. Nature climate change, 1 , 46.

Sperber, D., Clément, F., Heintz, C., Mascaro, O., Mercier, H., Origgi, G., \& Wilson, D. (2010). Epistemic vigilance. Mind \& Language, 25(4), 359-393.

Stanovich, K. E., \& West, R. F. (1997). Reasoning independently of prior belief and individual differences in actively open-minded thinking. Journal of Educational Psychology, 89(2), 342-357.

Sterman, J. D., \& Sweeney, L. B. (2007). Understanding public complacency about climate change: Adults' mental models of climate change violate conservation of matter. Climatic change, 80(3-4), 213-238.

Taber, C. S., \& Lodge, M. (2006). Motivated skepticism in the evaluation of political beliefs. American Journal of Political Science, 50,755-769.

Thaler, R. H., \& Sunstein, C. R. (2009). Nudge: Improving decisions about health, wealth, and happiness. Penguin.

Thomson, K. S., \& Oppenheimer, D. M. (2016). Investigating an alternate form of the cognitive reflection test. Judgment and Decision making, 11(1), 99.

Tobler, C., Visschers, V. H. M. and Siegrist, M. (2012). 'Consumers' knowledge about climate change'. Climatic Change, 114(2), 189-209. https://doi.org/10.1007/s10584011-0393-1.

Trémolière, B., \& Djeriouat, H. (2019). Love is not exactly blind, at least for some people: Analytic cognitive style predicts romantic beliefs. Personality and Individual Differences, 145, 119-131

Van der Linden, S. (2015). The social-psychological determinants of climate change risk perceptions: Towards a comprehensive model. Journal of Environmental Psychology, $41,112-124$ 
Weber, E. U., \& Stern, P. C. (2011). Public understanding of climate change in the United States. American Psychologist, 66(4), 315.

Whitmarsh, L. (2011). Scepticism and uncertainty about climate change: Dimensions, determinants and change over time. Global environmental change, 21(2), 690-700.

Zaval, L., Keenan, E. A., Johnson, E. J., \& Weber, E. U. (2014). How warm days increase belief in global warming. Nature Climate Change, 4(2), 143. 